\section{Quantitative Nutrient Management Reduces Nitrate Accumulation in Hydroponic Butterhead Lettuces Grown under Artificial Lighting}

\author{
Yuki Sago ${ }^{1}$ and Airi Shigemura \\ Faculty of Agriculture, Yamaguchi University, Yoshida 1677-1, Yamaguchi \\ 753-8515, Japan
}

Additional index words. environmental control, closed system, plant factory, soil-less cultivation, nitrate absorption model

\begin{abstract}
To reduce nitrate concentrations in vegetables grown under artificial lighting, we determined nitrate accumulation under various conditions of nitrate availability. Butterhead lettuce plants were grown with nutrient solutions of various concentrations, which were maintained according to electrical conductivity (EC) throughout the cultivation period. Under these conditions, growth in nutrient solutions with lower EC led to slight decreases in nitrate concentrations in leaves, but also decreased fresh and dry weights of shoots, leading to the risk of a yield loss under EC control management (ECM). By contrast, when total nitrate requirement was supplied only at the start of cultivation, nitrate concentrations in leaves were decreased significantly with only slightly reduced plant growth. Hence, marketable-sized butterhead lettuces with lower nitrate concentrations can be produced by supplying total nitrate requirements in the nutrient solution at the start of cultivation.
\end{abstract}

Environmentally controlled closed cultivation systems with artificial lighting, such as plant factories, are becoming important for stable vegetable production because they allow continuous cultivation of crops and protect crops from the weather and limit the risk of disease and insect damage, leading to high yields. In closed system, to increase the plant growth rate is a commonly used strategy to maximize the production efficiency (Higashi et al., 2015; Murase et al., 2015), and it is achieved by controlling environmental factors such as light intensity and quality, temperature, and nutrient availability. The optimization of nutrient management in hydroponic solutions is particularly important in improving plant growth rate without increasing the electricity cost.

To improve plant growth in conventional hydroponic cultures, plants are grown in nutrient solutions with constant and relatively high EC. EC control management strategies are employed to ensure sustained nutrient contents in culture systems. However, this method can lead to excessive nitrate absorption by roots and high nitrate concentrations in

Received for publication 22 Aug. 2017. Accepted for publication 15 Dec. 2017.

This study was supported by a Grant-in-Aid for Scientific Research (No. 26850157) and "Program to Disseminate Tenure Tracking System," MEXT, Japan.

We would like to thank Yasuomi Ibaraki and Shinichi Ozaki of Yamaguchi University for their helpful discussions and suggestions.

${ }^{1}$ Corresponding author. E-mail: sago@yamaguchi-u. ac.jp. vegetable leaves. Furthermore, surplus solutions from ECM systems with relatively high $\mathrm{EC}$ are drained into the environment, resulting in pollution of surface and groundwater.

Nitrate accumulates readily in leaves under conditions of high nitrate absorption, and nitrate accumulation contributes to decreases in soluble organic compounds under low light intensity through its osmotic functions (Blom-zandstra and Lampe, 1985). Therefore, nitrate concentrations tend to be higher in vegetables grown in hydroponic systems with low light intensity, such as closed systems with artificial lighting (Oka et al., 2017; Zhou et al., 2013). Furthermore, these growing conditions decrease nutritional quality with decreased sugar and vitamin $C$ levels (Fu et al., 2017; Kirimura et al., 2015). The consumption of nitrate-rich vegetables can lead to methemoglobinemia in animals and the formation of carcinogenic N-nitroso compounds (Mensinga et al., 2003). Thus, to prevent health risks, the upper limits for nitrate concentrations have been specified (European Commission, 2014).

Numerous methods for decreasing nitrate concentrations in leafy vegetables have been investigated previously, including the use of low nitrate concentrations in the nutrient solutions (Gent, 2003), interruption of nitrate supply a few days before harvest (Kirimura et al., 2015), manual control of nutrient supply (Andersen and Nielsen, 1992), the use of programmed nutrient supplementation (Asher and Blamey, 1987), changing the $\mathrm{N}$-form ratio of the nutrient solutions (Santamaria et al., 1997a, 1997b), applying low-temperature stresses to roots (Chadirin et al., 2011a, 2011b, 2012; Ito et al., 2015), and changing light conditions (Bian et al., 2016; Itoh et al., 2015; Samuoliene et al., 2009; Zhou et al., 2013). However, nitrate is the major form of nitrogen in the nutrient solution and plays an important role in lettuce growth (Ikeda and Osawa, 1980). Therefore, low nitrate concentrations in nutrient solutions can limit yields. Furthermore, changes in light conditions and interruptions of nutrient supply cause additional system and labor costs. Therefore, the development of new nutrient management methods is essential to prevent over supply and excess absorption of nitrate without causing remarkable growth suppression or increasing initial and running costs.

To prevent over-application of nutrients, the quantitative nutrient management (QNM) application was proposed for hydroponic vegetables (Li et al., 2014; Maruo et al., 2001; Matsuda et al., 2010, 2011; Pardossi et al., 2002; Takei and Suzuki, 2013; Terabayashi et al., 2004). Maruo et al. (2001) and Takei and Suzuki (2013) showed that nitrate concentrations are reduced in leaves by the application of QNM in spinach cultivars under greenhouse conditions and supplied nutrients every day or only at the start of cultivation. However, whereas nitrate absorption has a major impact on nitrate accumulation and vegetable yields, nitrate absorption by roots and nitrate accumulation in leaves have only rarely been studied using QNM in closed systems with artificial lighting. Thus, knowledge of the relationship between nitrate supply and nitrate accumulation is required to reduce nitrate concentrations in hydroponically grown vegetables.

Herein, we investigated the effectiveness of QNM by supplying sufficient nitrate for growth at the start of cultivation in a closed system with artificial lighting. Butterhead lettuces were grown in nutrient solutions with various EC and with differing amounts of nitrate at the start of cultivation, and the efficacy of QNM was compared with that of ECM by determining relationships between nitrate supply and nitrate accumulation. In addition, rates of nitrate absorption by roots were determined to characterize the dependence of nitrate absorption on nitrate concentrations in nutrient solutions.

\section{Materials and Methods}

Plant cultivation. All experiments were performed in a closed system with artificial lighting at the Faculty of Agriculture, Yamaguchi University, Japan. The room was equipped with two air conditioners (SZYA50CAV; Daikin Industries, Ltd., Japan), a dehumidifier (MJ-180JX; Mitsubishi Electric Corp., Japan), a carbon dioxide supply system, and a deep flow hydroponic cultivation system. Air temperature, relative humidity, and carbon dioxide concentration in the cultivation area were maintained at $20^{\circ} \mathrm{C}$, $60 \%$, and $1200 \mu \mathrm{mol} \cdot \mathrm{mol}^{-1}$, respectively. Butterhead lettuce (Lactuca sativa var. capitata L.) "Pansoma" (Syngenta Japan K.K., Japan) seeds were sown into polyurethane foam in plastic trays $(600 \times 300 \times 50 \mathrm{~mm})$ with nutrient solution 
Table 1. Nitrate concentrations in starter solution and cultivation under electrical conductivity (EC), EC control management (ECM), and quantitative nutrient management (QNM).

\begin{tabular}{|c|c|c|c|c|c|c|c|}
\hline & \multicolumn{4}{|c|}{ QNM } & \multicolumn{3}{|c|}{ ECM } \\
\hline & $3 / 8 \mathrm{U}$ & $4 / 8 \mathrm{U}$ & $6 / 8 \mathrm{U}$ & $1 \mathrm{U}$ & EC1.0 & EC2.0 & EC3.0 \\
\hline Nitrate contents in starter solution (mmol/plant) & 13.5 & 18 & 27 & 36 & 18 & 36 & 54 \\
\hline Nutrient supply during cultivation & \multicolumn{4}{|c|}{ Without nutrient supply during cultivation } & \multicolumn{3}{|c|}{ EC controlled by adding concentrated solution } \\
\hline
\end{tabular}
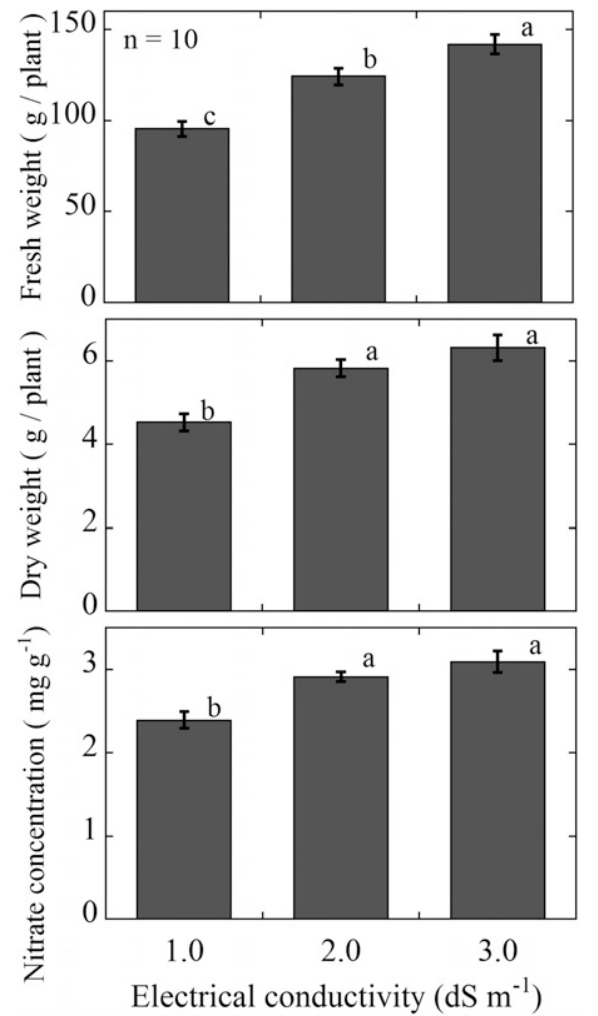

Fig. 1. Fresh weights, dry weights, and nitrate concentrations of butterhead lettuce shoots grown under different electrical conductivity of nutrient solution at $35 \mathrm{~d}$ after sowing; means of 10 plants are shown with SEs. Means with the same letter are not significantly different; Tukey's honestly significant difference test; $P<0.01$.

and were cultivated for $35 \mathrm{~d}$ in all experiments. Two days after sowing, seedlings were illuminated with continuous light using white fluorescent lamps (FHF32EX-N-H; Panasonic Corp., Japan). We used the OAT House SAprescription nutrient solution (OAT Agrio Co., Ltd., Japan) containing 17.1-mM $\mathrm{NO}_{3}^{-}, 1.1-\mathrm{mm}$ $\mathrm{PO}_{4}{ }^{3-}, 1.6-\mathrm{mM} \mathrm{SO}_{4}{ }^{2-}, 8.4-\mathrm{mm} \mathrm{K}^{+}, 1.5-\mathrm{mM} \mathrm{Mg}^{2+}$, and 3.9-mM $\mathrm{Ca}^{2+}$. Photosynthetic photon flux density (PPFD) at surfaces of polyurethane foams was set to $200 \mu \mathrm{mol} \cdot \mathrm{m}^{-2} \cdot \mathrm{s}^{-1}$. Ten days after sowing, seedlings were transplanted into 24-hole floating panels $(900 \times 600 \times 50 \mathrm{~mm})$ and were installed in hydroponic cultivation beds $(1200 \times 600 \times 200 \mathrm{~mm})$ containing $50 \mathrm{~L}$ of nutrient solution at a depth of $70 \mathrm{~mm}$. Four fluorescent lamps were mounted above each bed, and the PPFD at the surface of each panel was set at $200 \mu \mathrm{mol} \cdot \mathrm{m}^{-2} \cdot \mathrm{s}^{-1}$ by adjusting the distance between the panels and the lamps to $280 \mathrm{~mm}$. To increase growth rates, plants were exposed to continuous light for all treatments, as frequently employed in plant factories. For ECM,
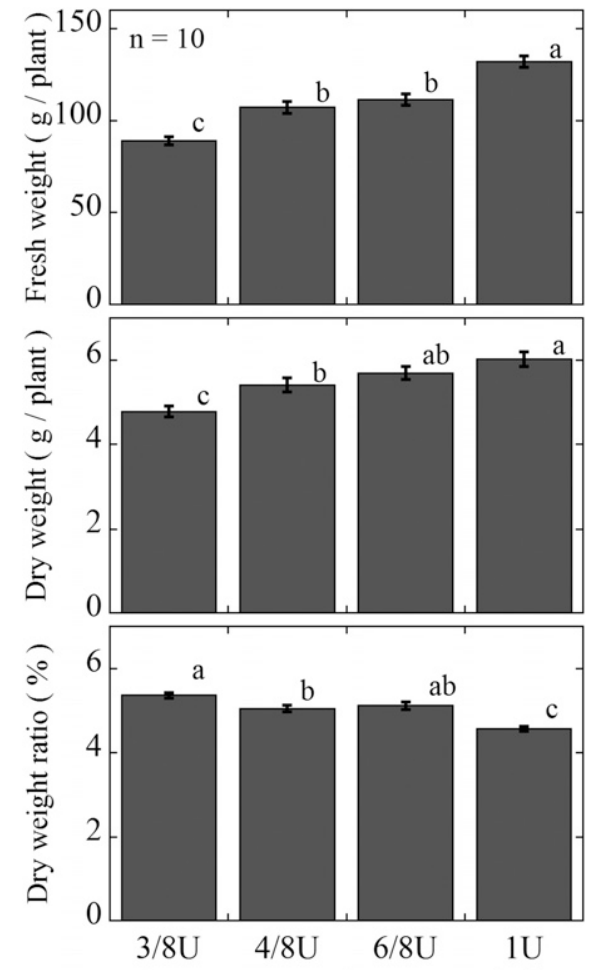

Nitrate contents in starter solution

Fig. 2. Fresh weights, dry weights, and dry weight ratios of butterhead lettuce shoots after $35 \mathrm{~d}$ growth with various initial nitrate contents in nutrient solution; means of 10 plants are shown with SES. Means with the same letter are not significantly different; Tukey's honestly significant difference test; $P<0.01$.

plants were grown with constant but differing nitrate concentrations in nutrient solution, which were kept at EC values of 1.0, 2.0, and $3.0 \mathrm{dS} \cdot \mathrm{m}^{-1}$ using a conductivity meter $(\mathrm{CM}$ 31P; DKK-TOA Co., Japan) and additions of concentrated solutions throughout the cultivation period (Table 1). For QNM, the plants were grown in the presence of $13.5,18,27$, and $36 \mathrm{mmol}$ of nitrate per plant $(3 / 8 \mathrm{U}, 4 / 8 \mathrm{U}, 6 / 8 \mathrm{U}$, and $1 \mathrm{U}$, respectively) at the start of cultivation and no further nitrate was provided. Water volumes in all culture beds were kept constant by adding distilled water. Consequently, the concentration of nutrients including nitrate and other nutrients in the nutrient solution decreased because of root absorptive function. Relative compositions of nutrient solutions for starter and concentrated solutions were the same as those used to cultivate seedlings. Nutrient solutions were circulated and aerated continuously in the cultivation bed using a water pump (Compact 600; Eheim GmbH \& Co. KG., Germany) and were sampled every day for analyses of nitrate concentrations using ion chromatography (ICA-2000; DKK-TOA Co.). Total nitrogen requirements for plant growth were estimated from direct determinations of nitrate absorption in plants of marketable size.

Sample measurements. Leaf color intensities were assessed according to light transmittance using a chlorophyll meter (SPAD-502; Minolta Camera Co., Ltd., Japan) at $35 \mathrm{~d}$ after sowing and were expressed as SPAD index values. A total of 20 plants were harvested in each treatment at $35 \mathrm{~d}$ after sowing and shoots were sampled by cutting below the cotyledonary node for measurements of fresh weights. Subsequently, 10 shoot samples were dried at $90{ }^{\circ} \mathrm{C}$ for $48 \mathrm{~h}$ and dry weights were recorded.

The remaining 10 shoot samples were used in determinations of nitrate and total soluble solids. Nitrate concentrations were determined using the methods described by Matsuda et al. (2009). Briefly, shoots were cut into pieces and mixed thoroughly, and 5-g samples were extracted and deproteinized by sonication for $20 \mathrm{~min}$ at $80{ }^{\circ} \mathrm{C}$ in solutions comprising $16 \mathrm{~mL}$ of 0.5 -M sodium hydroxide, $16 \mathrm{~mL}$ of $9 \%$ zinc acetate, and $30 \mathrm{~mL}$ of distilled water. After cooling to room temperature, extracts were diluted to $100 \mathrm{~mL}$, filtered through filter papers (Whatman No. 5) and membrane filters $(0.22 \mu \mathrm{m})$, and nitrate concentrations were then determined using ion chromatography. Juices were extracted from the remaining shoots using a mortar and pestle and total soluble solid contents were determined and expressed as $\%$ Brix using a digital refractometer (PAL-1; Atago Co., Ltd., Japan).

Measurements of water and nitrate absorption. Rates of water and nitrate absorption through the roots of butterhead lettuce plants were determined using a previously described system (Sago, 2016, Sago et al., 2011a) with minor modifications. The system comprises a root chamber $(70 \times 70 \times$ $70 \mathrm{~mm})$, a solution tank $(100 \mathrm{~mL})$, an electronic balance (FZ-300i; A\&D Co., Japan), a tubing pump (MP-1983E; As One Corp., Japan), and silicon tubes (4-mm diameter) and circulates nutrient solution continuously between the root chamber and the solution tank. The nutrient solution overflows from the root chamber into the solution tank, and the volume of the nutrient solution in the root chamber remains constant. Water absorption rates in individual plants were calculated according to changes in nutrient solution volumes in the solution tank over time. Nitrate absorption rates were determined on the basis of nitrate balance analysis of nutrient solution in the system during the measurement. Nitrate contents were determined using ion chromatography. Before harvesting at $35 \mathrm{~d}$ after sowing, plants grown 

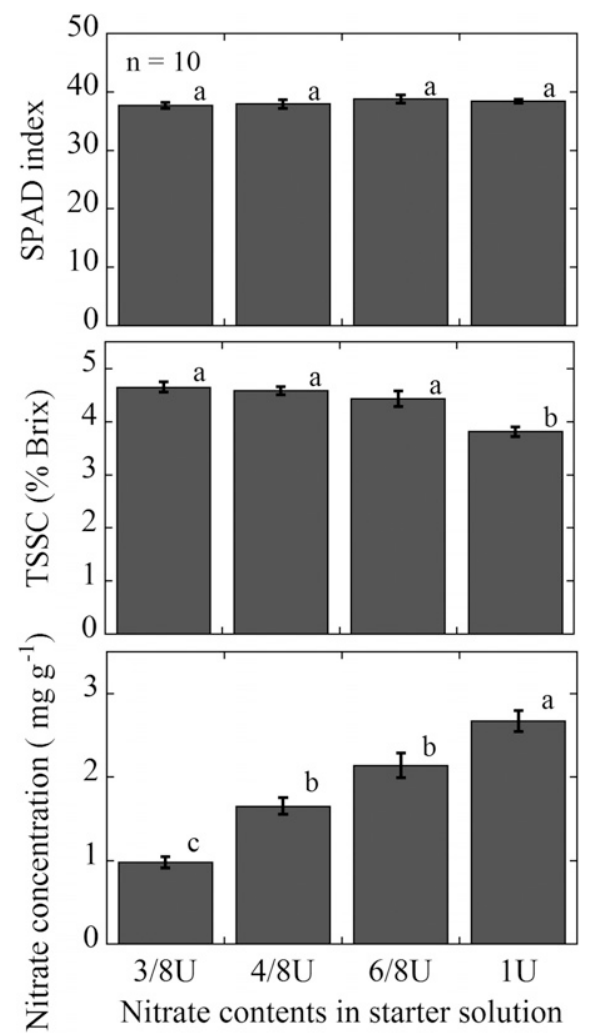

Fig. 3. SPAD indices, total soluble solids contents, and nitrate concentrations of butterhead lettuce shoots grown with various initial nitrate concentrations in nutrient solution at $35 \mathrm{~d}$ after sowing; means of 10 plants are shown with SES. Means with the same letter are not significantly different; Tukey's honestly significant difference test; $P<0.01$.

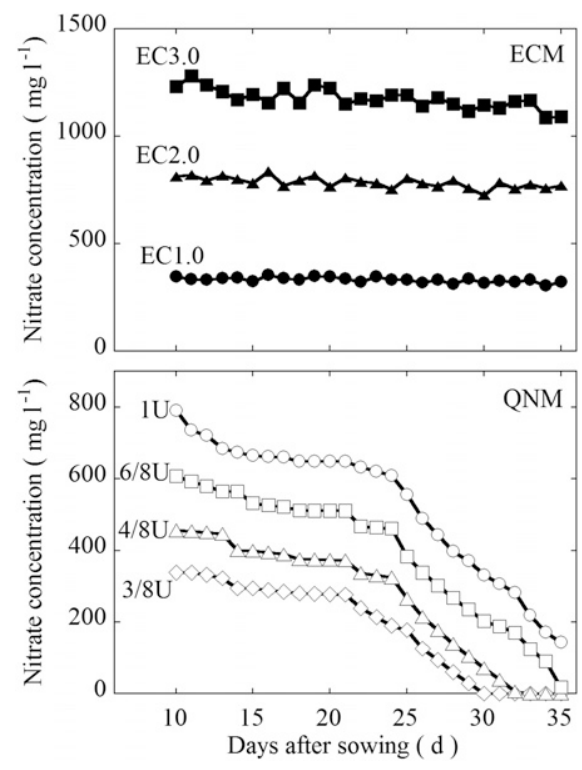

Fig. 4. Daily changes in nitrate concentrations in the nutrient solution under ECM and QNM. EC = electrical conductivity; $\mathrm{ECM}=\mathrm{EC}$ control management; QNM = quantitative nutrient management.

under $2.0 \mathrm{dS} \cdot \mathrm{m}^{-1} \mathrm{EC}$ in the ECM were transferred to the measuring device in a growth chamber (KCLP-1400ICT; Nippon Medical

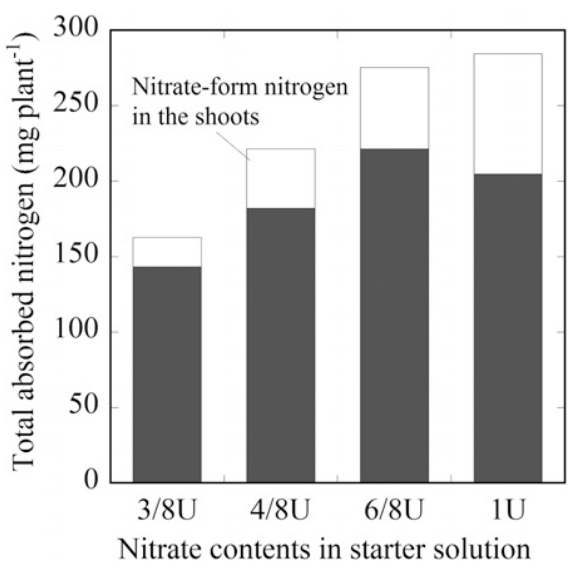

Fig. 5. Total nitrogen absorption under various nitrate supply conditions with quantitative nutrient management; white bars indicate concentrations of nitrate in shoots after respective treatments.

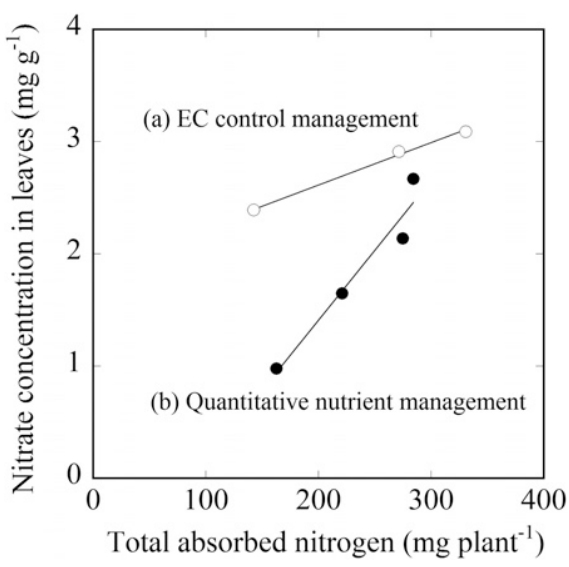

Fig. 6. Relationships between nitrate concentrations in leaves and total nitrogen absorption by plants grown with various nitrate contents of nutrient solutions with EC control management (a) and quantitative nutrient management (b); solid lines represent linear regressions; (a) $y=1.861+0.00376 x ; r=0.998 ; P<0.01$; (b) $y=-1.085+0.01246 x ; r=0.971 ; P<0.01$. $\mathrm{EC}=$ electrical conductivity.

\& Chemical Instruments Co., Ltd., Japan) at $20{ }^{\circ} \mathrm{C}$ and $60 \%$ humidity with 1200 $\mu \mathrm{mol} \cdot \mathrm{mol}^{-1}$ carbon dioxide and artificial light from white fluorescent lamps (FHF16EX$\mathrm{N}-\mathrm{H}$; Panasonic Co.) with PPFD of 200 $\mu \mathrm{mol} \cdot \mathrm{m}^{-2} \cdot \mathrm{s}^{-1}$ at the uppermost leaf. The $\mathrm{pH}$ of nutrient solutions was adjusted to 6.2 , and rates of water and nitrate absorption were determined three times in each of 10 plants for $20 \mathrm{~min}$. Nitrate absorption rates at various nitrate concentrations were fitted to a regression curve of concentration-dependent model which modified from the Michaelis-Menten equation (Sago et al., 2011b) as:

$$
Q_{\mathrm{NO}_{3}}=\frac{Q_{\max } \cdot\left[\mathrm{NO}_{3}^{-}\right]_{\mathrm{S}}}{K_{\mathrm{M}}+\left[\mathrm{NO}_{3}{ }^{-}\right]_{\mathrm{S}}},
$$

where $Q_{\mathrm{NO}_{3}}$ is the nitrate absorption rate through roots, $\left[\mathrm{NO}_{3}{ }^{-}\right]_{\mathrm{S}}$ is the nitrate concentration in the nutrient solution, $Q_{\max }$ is the maximum rate of nitrate absorption, and $K_{\mathrm{M}}$ is the Michaelis-Menten constant.

In addition, mass flow rates of nitrates to roots, which are the rates of nitrate transport from the nutrient solution around the root surface to root cortex apoplast, were calculated from the products of water absorption rates and nitrate concentrations in the nutrient solution. During active nitrate absorption, nitrate absorption rates exceed mass flow rates of nitrates to roots. Hence, in the transpiration integrated model (Nomiyama et al., 2017; Sago et al., 2011c), apparent uptake concentrations were greater than those in nutrient solutions.

Data analysis. Data were collected from 10 plants for each group. Differences were identified using analysis of variance with post hoc multiple comparison tests (Tukey's honestly significant difference; $P<0.05$ ), and correlation and regression analyses were performed using Kaleida Graph (Synergy Software) statistical software.

\section{Results and Discussion}

In Fig. 1, we present fresh weights, dry weights, and nitrate concentrations of butterhead lettuce shoots at $35 \mathrm{~d}$ after sowing under different EC of nutrient solution with ECM. Under these conditions, fresh weights of shoots decreased significantly with decreases in EC of the solution. Although fresh weights reached marketable levels $(>80 \mathrm{~g})$ under all treatments, the fresh weights of shoots grown under 1.0 and $2.0 \mathrm{dS} \cdot \mathrm{m}^{-1}$ EC were $33 \%$ and $13 \%$ lower, respectively, than those of plants grown under $3.0 \mathrm{dS} \cdot \mathrm{m}^{-1}$ EC. Similarly, dry shoot weights and nitrate concentrations were reduced with decreasing EC of nutrient solutions. However, nitrate concentrations in leaves reached specified upper limits $(<3.0$ $\left.5.0 \mathrm{mg} \cdot \mathrm{g}^{-1}\right)$ in lettuce leaves grown under EC conditions of $3.0 \mathrm{dS} \cdot \mathrm{m}^{-1}$ and were $23 \%$ and $6 \%$ lower in plants grown under 1.0 and 2.0 $\mathrm{dS} \cdot \mathrm{m}^{-1} \mathrm{EC}$, respectively. Leaf nitrate concentrations were only slightly lower under conditions of reduced EC, growth rates of butterhead lettuces were decreased remarkably, indicating the risk of yield loss at low nitrate concentrations under the conditions of ECM.

Figure 2 shows fresh weights, dry weights, and dry matter ratios of butterhead lettuce shoots at $35 \mathrm{~d}$ after sowing with differing initial nitrate contents under the conditions of QNM. Fresh shoot weights were significantly lower after growth in nitraterestricted solutions but reached marketable levels $(>80 \mathrm{~g})$ under all of the present conditions. Specifically, fresh weights of shoots grown under $3 / 8 \mathrm{U}, 4 / 8 \mathrm{U}$, and $6 / 8 \mathrm{U}$ were $32 \%, 19 \%$, and $16 \%$ lower, respectively, than those of plants grown under 1U. Similarly, dry weights of shoots were decreased under nitrate-restrictive conditions and dry matter ratios were consequently increased. Taken with previous studies (Broadley et al., 2003; Kirimura et al., 2015), the present data suggest reduced carbon assimilation under nitrate-limited conditions. 

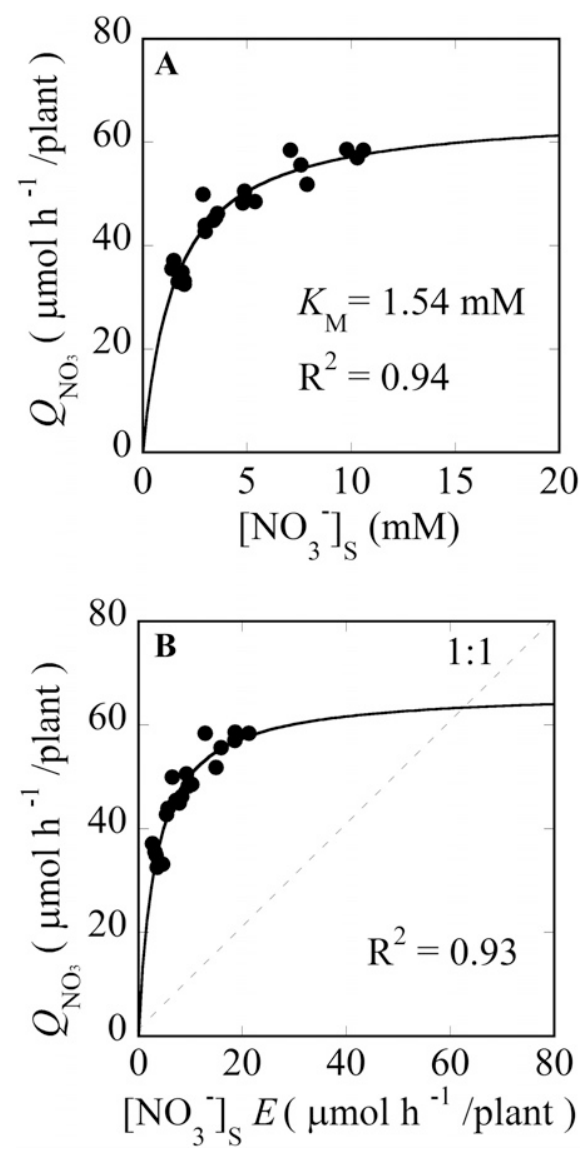

Fig. 7. Rates of nitrate absorption $\left(Q_{\mathrm{NO}_{3}}\right)$ through butterhead lettuce roots with various nitrate concentrations in nutrient solutions $\left(\left[\mathrm{NO}_{3}{ }^{-}\right]_{\mathrm{S}}\right)$ and nitrate mass flow through roots $\left(\left[\mathrm{NO}_{3}{ }^{-}\right]_{\mathrm{S}} \cdot E\right)$; solid lines represent nonlinear regression fitting to $Q_{\mathrm{NO}_{3}}$ in the concentration-dependent model (A) and in the transpiration integrated model (B). Michaelis-Menten constant $\left(K_{\mathrm{M}}\right)$ and coefficients of determination $\left(R^{2}\right)$ are shown and the broken line indicates $Q_{\mathrm{NO}_{3}}=\left[\mathrm{NO}_{3}{ }^{-}\right]_{\mathrm{S}} \cdot E$.

After QNM of butterhead lettuce shoots under varying nitrate concentrations of initial nutrient solutions, we determined SPAD indices, total soluble solids contents, and nitrate concentrations (Fig. 3). No significant differences in SPAD indices were observed between treatments, suggesting that the negative effects of limited nitrate supply on leaf colors were limited under these experiment conditions. However, total soluble solid contents were significantly lower in the $1 \mathrm{U}$ group than the other groups and were negatively correlated with nitrate concentrations as reported previously (Kirimura et al., 2015). Moreover, nitrate concentrations in shoots decreased by $63 \%, 38 \%$, and $20 \%$ under limited nitrate supply conditions of $3 / 8 \mathrm{U}$, $4 / 8 \mathrm{U}$, and $6 / 8 \mathrm{U}$ groups, respectively, compared with plants of the $1 \mathrm{U}$ group. Furthermore, nitrate concentrations of less than $1 \mathrm{mg} \cdot \mathrm{g}^{-1}$ fresh weight were observed in shoots of the 3/8U group and were lower following QNM than following ECM under limited nitrate supply conditions.

Figure 4 shows daily nitrate concentration changes in nutrient solutions during ECM and QNM. Nitrate concentrations in nutrient solutions under ECM were almost constant between treatments but decreased gradually and linearly during QNM and reached zero at a few days before harvest of plants grown with limited nitrate availability.

Similar to nitrate concentrations in leaves, total absorbed nitrogen per plant (Fig. 5) decreased with limitations of nitrate supply conditions during QNM. Thus, we determined relationships between nitrate concentrations in shoots and total nitrogen absorption after growth under ECM and QNM conditions with various nitrate concentrations (Fig. 6). In these experiments, nitrate concentrations in shoots decreased with reductions in absorbed nitrogen, and this tendency was stronger among plants grown under the conditions of QNM than among those grown with ECM. These results indicate that butterhead lettuces of marketable size and lower nitrate concentrations can be produced by supplying the total nitrogen requirements $(150-200 \mathrm{mg} /$ plant) in the nutrient solution at the start of cultivation.

The nitrate absorption rates in the butterhead lettuce roots increased with increasing nitrate concentration in a concentrationdependent manner (Fig. 7A). Furthermore, higher efficiency of nitrate absorption under low nitrate concentration in the nutrient solution was indicated by low MichaelisMenten constants from regression models because the Michaelis-Menten constant is negatively correlated with root nitrate absorptive function under conditions of lower nitrate availability. Accordingly, these results suggest that nitrate absorption rates are not influenced by nitrate concentrations at the concentrations tested herein. Maruo et al. (2002) similarly reported relatively stable nitrate absorption rates by butterhead lettuce roots within a comparatively wide range of nutrient concentrations. Therefore, the diminished effects of nitrate limitations under ECM likely reflect sustained nitrate absorption under various nitrate concentrations. By contrast, QNM with limited nitrate supply led to marked suppression of nitrate absorption for the final days before harvest. Furthermore, under conditions of lower nitrate mass flow rates through roots, nitrate absorption rates were higher than nitrate mass flow (Fig. 7B). These data suggest that butterhead lettuce roots actively absorb nitrate under QNM, causing linear decreases of nitrate concentrations in nutrient solution and depleting nitrate to trace levels by a few days before harvest.

Taken together, we conclude that when total nitrate requirements are supplied at the start of cultivation, nitrate concentrations in leaves decrease significantly with only slight reductions in fresh and dry shoot weights. Therefore, marketable-sized butterhead lettuces can be produced with lower nitrate concentrations by supplying total nitrate requirements in the nutrient solution at the start of cultivation in environmentally controlled closed cultivation systems with artificial lighting.

\section{Literature Cited}

Andersen, L. and N.E. Nielsen. 1992. A new cultivation method for the production of vegetables with low content of nitrate. Scientia Hort. 49:167-171.

Asher, C.J. and F.P. Blamey. 1987. Experimental control of plant nutrient status using programmed nutrient addition. J. Plant Nutr. 10:1371-1380.

Bian, Z., R. Cheng, Q. Yang, and J. Wang. 2016. Continuous light from red, blue, and green light-emitting diodes reduces nitrate content and enhances phytochemical concentrations and antioxidant capacity in lettuce. J. Amer. Soc. Hort. Sci. 141:186-195.

Blom-zandstra, M. and J.E.M. Lampe. 1985. The role of nitrate in the osmoregulation of lettuce (Lactuca sativa L.) grown at different light intensities. J. Expt. Bot. 36:1043-1052.

Broadley, M.R., I. Seginer, A. Burns, A.J. EscobarGutiérrez, I.G. Burns, and P.J. White. 2003. The nitrogen and nitrate economy of butterhead lettuce (Lactuca sativa var. capitata L.). J. Expt. Bot. 54:2081-2090.

Chadirin, Y., K. Hidaka, Y. Sago, T. Wajima, and M. Kitano. 2011a. Application of temperature stress to roots of spinach I. Effect of the low temperature stress on quality. Environ. Control Biol. 49:133-139.

Chadirin, Y., K. Hidaka, T. Takahashi, Y. Sago, T. Wajima, and M. Kitano. 2011b. Application of temperature stress to root zone of spinach II. Effect of the high temperature pre-treatment on quality. Environ. Control Biol. 49:157-164.

Chadirin, Y., Y. Sago, K. Hidaka, T. Wajima, and M. Kitano. 2012. Application of temperature stress to root zone of spinach III. Effective method for short term application of low and high temperature stresses to roots. Environ. Control Biol. 50:199-207.

European Commission. 2014. Commission regulation (EU) No. 488/2014 amending regulation (EC) No. 1881/2006 as regards maximum levels for nitrates in foodstuffs. Offic. J. Eur. Union L 138:75-79.

Fu, Y., H. Li, J. Yu, H. Liu, Z. Cao, N.S. Manukovsky, and H. Liu. 2017. Interaction effects of light intensity and nitrogen concentration on growth, photosynthetic characteristics and quality of lettuce (Lactuca sativa L. var. youmaicai). Scientia Hort. 214:51-57.

Gent, M.P.N. 2003. Solution electrical conductivity and ratio of nitrate to other nutrients affect accumulation of nitrate in hydroponic lettuce. HortScience 38:222-227.

Higashi, T., S. Nishikawa, N. Okamura, and H Fukuda. 2015. Evaluation of growth under non$24 \mathrm{~h}$ period lighting conditions in Lactuca sativa L. Environ. Control Biol. 53:7-12.

Ikeda, H. and T. Osawa. 1980. Comparison of adaptability to nitrogen source among vegetable crops. J. Jpn. Soc. Hort. Sci. 48:435-442.

Ito, A., H. Shimizu, R. Hiroki, H. Nakashima, J. Miyasaka, and K. Ohdoi. 2015. Quantitative relationship of the nutritional quality of spinach with temperature and duration in root area chilling treatment. Environ. Control Biol. 53:35-42.

Itoh, H., K. Nomura, N. Shiraishi, Y. Uno, S. Kuroki, and K. Ayata. 2015. Continuous measurement of nitrate concentration in whole lettuce plant by visible-near-infrared spectroscopy. Environ. Control Biol. 53:205-215.

Kirimura, S., K. Kondo, N. Nakata, T. Yamaguchi, T. Wajima, and N. Matsuzoe. 2015. Effect of preharvest withdrawal of fertilizer component on growth, nitrate concentration, and total sugar content of Mizuna (Brassica rapa L. Japonica 
Group) in a hydroponic system. J. Sci. High Tech. Agr. 27:144-151. [in Japanese with English abstr.].

Li, H., T. Inokuchi, T. Nagaoka, M. Tamura, S. Hamada, S. Suzuki, S. Date, and Y. Fujime. 2014. $\mathrm{NO}_{3}{ }^{-}$requirement and the quantitative management method of nutrient solution based on $\mathrm{NO}_{3}^{-}$supply in hydroponic culture of radish plants. J. Jpn. Soc. Hort. Sci. 83:44-51.

Maruo, T., H. Hoshi, Y. Shinohara, and T. Ito. 2001. Quantitative nutrient management at low concentration condition in NFT spinach culture. Acta Hort. 548:133-140.

Maruo, T., Y. Shinohara, M. Iwata, and T. Ito. 2002. Effects of nutrient concentration on the absorption of N, P and K by lettuce cultured in NFT system. J. Jpn. Soc. Hort. Sci. 71:675682. [in Japanese with English abstr.].

Matsuda, R., K. Suzuki, Y. Nakano, H. Sasaki, and M. Takaichi. 2010. Daily based quantitative nutrient management in rockwool hydroponics: Growth and yield of tomato and nutrient use at elevated $\mathrm{CO}_{2}$. J. Agr. Meteorol. 66:217-226.

Matsuda, R., K. Suzuki, Y. Nakano, H. Sasaki, and M. Takaichi. 2011. Nutrient supply and fruit yields in tomato rockwool hydroponics under daily quantitative nutrient management: Analysis and evaluation based on leaf area index. J. Agr. Meterol. 67:117-126.

Matsuda, R., T. Watanabe, A. Ikarashi, Y. Shiramasa, and T. Maitani. 2009. Estimation of the daily intake of nitrate based on analysis of total diet samples. Food Hyg. Saf. Sci. 50:29-33. [in Japanese with English abstr.].

Mensinga, T.T., G.J. Speijers, and J. Meulenbelt. 2003. Health implications of exposure to environmental nitrogenous compounds. Toxicol. Rev. 22:41-51.
Murase, H., B. Helm, and S. Oke. 2015. Investigation of a scanning laser projector as an energyefficient light source in plant production. Environ. Control Biol. 53:71-76.

Nomiyama, R., D. Yasutake, Y. Sago, and M. Kitano. 2017. Application of transpiration integrated model to simulation of dynamics of ion absorption by tomato roots growing in soilless culture. Environ. Control Biol. 55:29-35.

Oka, Y., I. Hirayama, M. Yoshikawa, T. Yokoyama, K. Iida, K. Iwakoshi, A. Suzuki, M. Yanagihara, Y. Segawa, S. Kukimoto, and H. Hamada. 2017. Survey of nitrate ion concentrations in vegetables cultivated in plant factories: Comparison with open-culture vegetables. Food Hyg. Saf. Sci. 58:49-58. [in Japanese with English abstr.].

Pardossi, A., F. Malorgio, L. Incrocci, C.A. Campiotti, and F. Tognoni. 2002. A comparison between two methods to control nutrient delivery to greenhouse melons grown in recirculating nutrient solution culture. Scientia Hort. 92:89-95.

Sago, Y., D. Yasutake, K. Hidaka, E. Yasunaga, T. Eguchi, S. Yoshida, and M. Kitano. 2011a. Kinetics of root ion absorption affected by environmental factors and transpiration I. Measurement system for intact roots. Environ. Control Biol. 49:23-31.

Sago, Y., D. Yasutake, K. Hidaka, E. Yasunaga, T. Eguchi, S. Yoshida, and M. Kitano. 2011b. Kinetics of root ion absorption affected by environmental factors and transpiration II. Environmental effects and a concentration-dependent model. Environ. Control Biol. 49:32-40.

Sago, Y., D. Yasutake, K. Hidaka, E. Yasunaga, T. Eguchi, S. Yoshida, and M. Kitano. 2011c. Kinetics of root ion absorption affected by environmental factors and transpiration III. A kinetic model integrated with transpiration. Environ. Control Biol. 49:41-46.

Sago, Y. 2016. Effects of light intensity and growth rate on tipburn development and leaf calcium concentration in butterhead lettuce. HortScience 51:1087-1091.

Samuoliene, G., A. Urbonavičiūte, P. Duchovskis, Z. Bliznikas, P. Vitta, and A. Žukauskas. 2009. Decrease in nitrate concentration in leafy vegetables under a solid-state illuminator. HortScience 44:1857-1860.

Santamaria, P., A. Elia, and M. Gonnella. 1997a. Changes in nitrate accumulation and growth of endive plants during light period as affected by nitrogen level and form. J. Plant Nutr. 20:12551266.

Santamaria, P., A. Elia, M. Gonnella, and F. Serio. 1997b. Effects of two N levels and two NH4+: NO3- ratios on endive (Cichorium endivia $\mathrm{L}$. var. crispurm Hegi). I. Growth, yield and water use. Adv. Hort. Sci. 11:41-46.

Takei, H. and S. Suzuki. 2013. Nitrate requirement and the quantitative management method of nutrient solution based on the nitrate supply in hydroponic culture of Spinach plants. Sci. Rpt. Fac. Agr. Meijo Univ. 49:25-32.

Terabayashi, S., T. Asaka, A. Tomaturi, S. Date, and Y. Fujime. 2004. Effect of the limited supply of nitrate and phosphate on nutrient uptake and fruit production of tomato ( $\mathrm{LyCO}-$ persicon esculentum Mill) in hydroponic culture. Hort. Res. 3:195-200. [in Japanese with English abstr.].

Zhou, W., W. Liu, and Q. Yang. 2013. Reducing nitrate content in lettuce by pre-harvest continuous light delivered by red and blue lightemitting diodes. J. Plant Nutr. 36:481-490. 